ReBEn, $35: 39-47,1982$

\title{
AVALIAÇÃo COMPARATIVA ENTRE duAS TéCNICAS de COLHEITA DE URINA PARA CULTURA BACTERIOLÓGICA EM MULHERES
}

\author{
Maria Helena Pessini de Oliveira* \\ Vera Heloisa Pileggi Vinha**
}

ReBEn/04

OLIVEIRA, M.H.P. e Colaboradora - Avaliação Comparativa entre Duas Técnicas de Colheita de Urina para Cultura Bacteriológica em Mulheres. Rev. Bras. Enf.; DF, $35: 39-47,1982$.

\section{RESUMO}

Estudaram-Se 50 pacientes atendidos no ambulatório do Hospital das Clínicas da Faculdade de Medicina de Ribeirão Preto e encaminhadas para colheita de urocultura. As mesmas pacientes submeteram-se a duas 'técnicas de colheita de urina, jacto médio, no espaço de 24 horas (técnica I), higiene íntima feita pela própria paciente, utilizando água corrente e sabão neutro e técnica II, técnica asséptica feita por um profissional de enfermagem.

A técnica I satisfez $81,86 \%$ das pacientes, independente da idade, nível de escclaridade, estado civil e religião.

Os resultados microbiológicos tiveram a mesma eficácia em ambas as 'técnicas.

\section{INTRODUÇÃO}

O exame bacteriológico é indispensável para que se possa firmar com segurança a presença de infecção no trato urinário ALMEIDA (1967), podendose, através dele, estabelecer diagnóstico, pelo conhecimento do agente etiológico.

Um dos fatores importantes para se chegar a um resultado fiel do exame bacteriológico é a técnica empregada para a colheita de urina para cultura, que sofre grandes variações, desde uma colheita sem qualquer cuidado com a assepsia OLIVEIRA (1979), até a punção suprapúbica.

Vários são os autores que descrevem a 'técnica da colheita de urina para cultura bacteriológica. Encontramos as técnicas de punção suprapúbica, cateterismo, limpeza asséptica dos genitais, higienização dos genitais com água e sabão feita pela própria paciente,

* Professor Assistente da Escola de Enfermagem de Ribeirão Preto - USP.

** Professor Assistente Doutor da Escola de Enfermagem de Ribeirão Preto - USP. 
OLIVEIRA, M.H.P. e Colaboradora - Avaliação Comparativa entre Duas Técnicas de Colheita de Urina para Cultura Bacteriológica em Mulheres. Rev. Bras. Enf.; DF, 35 : 39-47, 1982.

conseguindo-se, em todas, ræsultadoz bacteriológicos aceitos pela maioria dos autores aqui mencionados.

Grandes são as divergências de técnicas de colheita de urina para cultura bacteriológica em mulheres empregadas em hospitais, ambulatórios e laboratórios OLIVEIRA (1979), convergindo as opiniões de vários autores apenas no que diz respeito à colheita do jacto média de urina para cultura bacteriológica. BRUNNER (1971), ROBERT (1977), KUNIN (1973), DU GAS (1978), COIMBRA (1976), LESSA (1977), MASON (1973), DAGUEY (1977).

De um modo geral, os autores preocupam-se em estudar ou estabelecer técnicas que satisfaçam apenas o ponto de vista microbiológico, uma vez que a presença de resultado duvidoso implica na repetição de um novo exame, bem como tratamento desnecessário para 0 paciente COIMBRA (1976), e ANGERAMI e cols. (1978).

A preocupação constante do profissional de saúde na busca de situações menos traumatizantes para a paciente, aliada à demora na execução da técnica, as grandes divergências de técnicas empregadas em ambulatórios e serviços de saúde, pensou-se em estudar uma técnica de urocultura mais simpli-ficada em mulheres, porém com resultados microbiológicos confiáveis.

Dados os raros estudos comparativos entre técnicas de colheita de urina para cultura bacteriológica é propósito deste trabalho realizar estudo comparativo entre as duas técnicas de colheita de urina, jacto médio, para cultura bactério em mulheres.

Técnica I - higiene íntima feita pela própria paciente, utilizando água corrente e sabão neutro.

Técnica II - Técnica asséptica, feita por um profissional de enferma-

* Sterilderm (R), DARRow. gem utilizando cloreto de tetrametilamônio * e soro fisiológico.

\section{MATERIAL E MÉTODO}

Foram incluídas no trabalho 50 pacientes entre 10 a 70 anos de idade, matriculadas no Hospital das Clínicas de Ribeirão Preto-USP, portadoras de um pedido de exame de urina para cultura bacteriológica. As mesmas pacientes submeteram-se às duas técnicas de colheita de urina para cultura, jasto médio, no espaço de 24 horas.

No primeiro dia, no período da manhã, as pacientes que referiam vontade de urinar eram levadas até o banheiro, onde recebiam orientação quanto à finalidade do exame de urina para cultura bacteriológica, de como proceder à técnica I, a higiene intima com água corrente e sabão neutro realizados por elas mesmas, ou seja, o que fazem habitualmente no dcmicílio, porém com maior rigor.

Para a realizacão da técnica $I$, era necessário:

\section{MATERIAL:}

1. Pacote esterilizado contendo fralda, tubo de ensaio e rolha

2. Sabão neutro

3. Sabonete

4. Papel higiênico

5. Ducha

6. Suporte para tubo de ensaio

7. Recipiente de isopor com gelo

8. Fita adesiva.

A seguir, mostrava-se à paciente o material a ser utilizado, sua disposição e o funcionamento da ducha. Abria-se o pacote esterilizado sobre um banco ao lado do vaso sanitário e ensinava à paciente como manuseá-lo para não contaminar.

A seguir, orientava-se a mulh $\approx r$ como fazer a higiene intima, porém 
OLIVEIRA, M.H.P. e Colaboradora - Avaliação Comparativa entre Duas Técnicas de Colheita de Urina para Cultura Bacteriológica em Mulheres. Rev. Bras. Enf.; DF, 35 : 39-47, 1982.

com maior rigor do que faz habitualmente em casa.

\section{PROCEDIMENTO}

1. Solicitava à paciente para:

1.1. Retirar a calça;

1.2. Lavar as mãos com sabonete;

1.3. Erguer a roupa procurando fixála na altura da sintura;

1.4. Sentar no vaso sanitário, afastar os joelhos o mais que puder;

1.5. Pegar a ducha que está ao lado do vaso sanitário e sobre a pia, com uma das mãos, acionar o botão de funcionamento e molhar os genitais;

OBSERVAÇÃO: Cuidado para não encostar a ducha na regiāo genital.

1.6. Pegar com a outra mão o sabão sobre a pia e ensaboar o monte pubiano, vulva e região perineal;

1.7. Descansar o sabão sobre a pia;

1.8. Lavar bem o monte pubiano, vulva, grandes e pequenos lábios, fúrcula vaginal e região perianal e finalmente o ânus;

1.9. Enxaguar a regiāo lavada e a mão;

1.10. Pegar com uma das mãos a fralda esterilizada;

1.11. Enxugar a regiāo vulvar com leve pressão;

1.12. Enxugar a região perianal e ânus com leve pressão;

1.13. Desprezar a fralda no recipíente para roupas sujas, ao lado do vaso sanitário;

1.14. Manter os joelhos bem afastados e erguer as nádegas do vaso sanitário, mantendo o corpo apoiado sobre as pernas semifletidas;

1.15. Pegar com uma das mãos o tubo de ensaio;

1.16. Iniciar a micção desprezando no vaso sanitário;
1.17. Colocar o tubo de ensaio com a bosa voltada para cima, na direção do jacto médio de urina, retirando uma amostra de mais ou menos $3 \mathrm{ml}$;

1.18. Entregar o tubo de ensaio para o profissional de enfermagem;

1.19. Terminar de urinar;

1.20. Lavar as mãos;

1.21. Recompor-se.

O tubo de ensaio era envolvido no papel higiênico, tampado, enxugado e identificado. A seguir, colocava-se no suporte de tubo de ensaio dentro do isopor com gelo.

No segundo dia, as mesmas pacientes referindo desejo de urinar, submetiam-se à tésnica II - técnica asséptica, feita por um profissional de enfermagem.

As pacientes eram orientadas quanto à finalidade da colheita da urina para cultura bacteriológica e quanto à técnica II.

Para a realização da téєnica II, era necessário:

\section{MATERIAL}

1. Pacote esterilizado, contendo:

- Cuba rim

- Pinça Pean

- Tubo de ensaio

- Cuba redonda

- Bolas de algodão

- Gazes

2. Luvas esterilizadas

3. Cuba rim forrada com papel

4. Vidro contendo Sterylderm

5. Comadre

6. Papel higiênico

7. Fita adesiva para identificação

\section{PROCEDIMENTO}

1. Lavar as mãos;

2. Solicitar à paciente para retirar a calça: 
OLIVEIRA, M.H.P. e Colaboradora - Avaliação Comparativa entre Duas Técnicas de Colheita de Urina para Cultura Bacteriológica em Mulheres. Rev. Bras. Enf.; DF, $35: 39-47,1982$.

3. Colocar a paciente em decúbito dorsal no divã, na posição ginecológica, protegendo-a com lençol, deixando exposta a região genital;

4. Colocar a comadre sob as nádegas da pacien'te;

5. Colocar sobre o divã: pacote de material esterilizado, luvas, os vidros de Sterylderm e soro fisiológico, e a cuba rim forrada com papel;

6. Abrir o pacote de material, aproximando-o da comadre;

7. Calçar luvas;

8. Pegar a pinça com uma das mãos e colocar as bolas de algodão na cuba redonda;

9. Despejar Sterylderm, com a outra mão, sobre as bolas de algodão, deixando-as encharcar;

10. Pinçar bolas de algodão com Sterylderm e passar no monte pubiano, desprezando o algodão na cuba forrada com papel;

11. Pinçar bolas de algodão com Sterylderm e limpar os grandes lábios, com movimentos contínuos, de cima para baixo, usando uma bola de algodão para cada lado, desprezando as usadas na cuba forrada com papel;

12. Pinçar bolas de algodão com Sterylderm e limpar os pequenos lábios, com movimentos contínuos, de cima para baixo, usando uma bola de algodão para cada lado, desprezando as usadas na cuba forrada de papel;

13. Pinçar bolas de algodão com Sterylderm e limpar o meato urinário, com movimentos rota'tórios, desprezando as bolas usadas na cuba forrada com papel;

14. Pinçar bolas de algodão com Sterylderm e limpar o períneo e região perianal, com movimentos contínuos, de cima para baixo, usando uma bola de algodão para cada lado, desprezando as usadas na cuba forrada com papel;
15. Esperar dois minutos e, a seguir, enxaguar o local limpo com soro fisiológico;

16. Pinçar gazes e enxugar o meato urinário e pequenos lábios, com movimentos, de cima para baixo, usando uma gaze para cada lado, desprezando as usadas na cuba forrada com papel;

17. Pinçar gazes e enxugar o monte pubiano e grandes lábios, com movimentos, de cima para baixo, usando uma gaze para cada lado, desprezando as usadas na cuba forrada com papel;

18. Pinçar gazes e enxugar o períneo e região perianal, com movimentos, de cima para baixo, usando uma gaze para cada lado e desprezando as usadas na cuba forrada com pape];

19. Descansar a pinça sobre o campo e afastar os materiais para os pés do divã;

20. Oferecer o braço direito para a paciente se apoiar e auxiliá-la a erguer o tórax do divã, a nádega da comadre, ficando agachada;

21. Pedir à paciente que lave as mãos para frente e sobre o divã;

22. Segurar com a mão direita a cuba rim, pelo lado de for'a, sem encostar na borda e no seu interior;

23. Pedir à paciente que inicie a micção na comadre, desprezando o primeiro jacto;

24. Retirar a comadre com a mão esquerda, puxando-a para trás da paciente e deixá-la sobre o divã;

25. Colocar a cuba rim sob o jacto de urina e esperar a paciente acabar de urinar;

26. Oferecer papel higiênico para a paciente se enxugar, levar a comadre no banheiro;

27. Colocar uma amostra da urina no tubo de ensaio Identificado, tampálo e colocá-lo no suporte de tubos de ensaio dentro do isopor com gelo; 
OLIVEIRA, M.H.P. e Colaboradora - Avaliação Comparativa entre Duas Técnicas de Colheita de Urina para Cultura Bacteriológica em Mulheres. Rev. Bras. Enf.; DF, 35 : 39-47, 1982.

28. Ajudar a paciente a descer do divã e recompor-se;

29. Recompor a unidade;

30. Lavar as mãos.

OBSERVAÇĀO: Para as pacientes que não conseguiam urinar na posição indicada, solicitava-se que a paciente descesse do divã, protegendo a área limpa com um campo esterilizado, encaminhando-a até o banheiro, onde iniciava a micção, desprezando o primeiro jacto no vaso sanitário, colhendo uma amostra na cuba rim esterilizada.

As amostras de urina foram conservadas em recipientes com gelo, num intervalo não superior a duas horas e encaminhadas para o laboratório, critérios estabelecidos por KUNIN (1973), KOURANY (1976) e DAGUET (1977).

\section{RESULTADOS E DISCUSSẢO}

As 50 pacientes participantes da pesquisa constituíram uma amostra satisfatória e representativa da real população feminina que habitualmente procura o Hospital das Clínicas. A realização da técnjca I satisfez seguramente $81,86 \%$ das pacientes, independentes do nível de escolaridade, estado civil, zona residencial, idade e religião.

Na tabela 1, encontramos $82 \%$ dos pacientes dentro da faixa etária de 20 a 50 anos. Quanto à zona residencial, $82 \%$ residiam em zona urbana e $18 \%$ na zona rural, o que permitiu comprovar que mesmo as não habitadas do conforto de água canalizada e banheiro dentro de casa, conseguiram realizar a técnica I sem maiores dificuldades.

Importante lembrar que a técnica I era precedida de uma orientação, dando subsídio à mulher de uma auto-higienização consciente $\Theta$ preventiva, uma vez que uma higiene incorreta pode le- var material fecal para a vagina e uretra. SOUTO e cols. (1977) e ROCHA (1968) ressaltaram a importância de uma higiene correta para a mulher após o uso do sanitário.

Quanto ao parecer das pacientes, encontramos $62 \%$ optando pela técnica I por ficar mais à vontade e ser confortável, enquanto que $18 \%$ ficaram indiferentes às duas técnicas, $20 \%$ optaram pela técnica II por ashá-la mais limpa (tabela 2).

É importante lembrar que se solicitava às pacientes que mantivessem a bexiga cheia, o que favorecia a micção em jacto. Para a técnica II, $56 \%$ das mulheres urinaram em jacto e $44 \%$ não o conseguiram e a urina escorreu pela nádega. Quanto à técnica I, $100 \%$ das pacientes conseguiram urinar em jacto, conservando a posição correta. $70 \%$ das pacientes conseguiram urinar na posição correta da técnica II, enquanto $30 \%$ tiveram que descer do divã para consegui-lo.

A análise microbiológica quantitativa das uroculturas agrupadas segundo os conceitos negativos (até $1.000 \mathrm{col} / \mathrm{ml}$ ); duvidoso $(1.000$ a $100.000 \mathrm{col} / \mathrm{ml})$ e positivo (maior ou igual a $100.000 \mathrm{col} / \mathrm{ml}$ ) apresentaram resultados praticamente iguais para as técnicas I e II. A diferença entre as duas foi da ordem de $2 \%$ para resultados negativos e duvidosos (Gráfico I).

O tempo médio gasto para execução da técnica I foi de 8,8 minutos por pessoa, enquanto que, para a técnica II, foi de 19,8 minutos (tabela 3). Levando-se em conta um laboratório ou um ambulatório de alto fluxo, a técnica I é altamente vantajosa, ganhando-se em tempo, mão-de-obra e pessoal. Quanto ao paciente, fora os inconvenientes implícitos na técnica II, ela ganha em rapidez de atendimento e tempo de permanência no local da colheita quando se usa a técnica $I$. 
OLIVEIRA, M.H.P. e Colaboradora - Avaliação Comparativa entre Duas Técnicas de Colheita de Urina para Cultura Bacteriológica em Mulheres. Rev. Bras. Enf.; DF. $35: 39-47,1982$.

Enquanto que, na técnica II, grande parte do tempo é consumida no preparo psicológico, na disposição do material, na elaboração da técnica, na espera da micção por parte da paciente.

Importante ressaltar que o custo operacional da técnics. II, sob todos os aspectos, foi mais onerosa do que a técnica I, a começar pela necessidade de maior aparelhamento no local da colheita e maior consumo de material.

$\mathrm{Na}$ tabela 4, relacionam-se os materiais necessários para a execução de ambas as técnicas e seus valores unitários e totais, orçando para a técnica I Cr\$25,85 e em Cr\$703,80, para a técnica II.

\section{CONCLUSÃO}

4.1. Das 50 mulheres submetidas às técnicas I e II, a técnisa I satisfez $81,86 \%$ das pacientes, independente da idade, nivel de escolaridade, estado civil e religião.
4.2. Quanto ao jacto de urina, foi mais facilmente obtido pela técnica I do que pela II.

4.2.1. $100 \%$ das pacientes conseguiram urinar $\in \mathrm{m}$ jacto pela técnica $\mathrm{I}$.

4.2.2. $56 \%$ das pacientes conseguiram urinar em jacto pela tésnica II.

4.2.3. $44 \%$ das pacientes, a urina saía gotejando ou escorrendo pela nádega.

4.3. Os resultados microbiológicos tiveram a mesma eficácia em ambas as técnicas. A diferença entre as duas técnicas foi da ordem de $2 \%$ para resultados negativos e duvidosos. $84 \%$ técnica I e $86 \%$ técnica II para resultado negativo. Resultado duvidoso, $8 \%$ técnica I e $6 \%$ técnica II.

4.4. A técnica II foi sob todos os aspectos mais onerosa que a técnica I, Gastaram-se em média 19,8 minutos para realizar a téc-

TABELA 1

POPULAÇÃO FEMININA, SEGUNDO GRUPO ETARIO E ZONAS RESIDENCIAIS

\begin{tabular}{|c|c|c|c|c|c|c|}
\hline ZONAS & \multicolumn{2}{|c|}{ URBAIIA } & \multicolumn{2}{|c|}{ RURAL } & \multicolumn{2}{|c|}{ TOTAL } \\
\hline ETARTU & $F$ & $\%$ & $\mathrm{~F}$ & $\%$ & $\mathbf{F}$ & $\pi$ \\
\hline $101-20$ & 1 & 2,00 & & & 1 & 2,00 \\
\hline $20 \longmapsto 30$ & 14 & 30,00 & 4 & 8,00 & 18 & 38,00 \\
\hline $301-40$ & 11 & 12,00 & 1 & 2,00 & 12 & 24,00 \\
\hline $40 \longmapsto 50$ & 12 & 24,00 & 1 & 2,00 & 13 & 26,00 \\
\hline 60 & 2 & 4,00 & 2 & 6,00 & 4 & 10,00 \\
\hline $60 \longleftarrow 70$ & 1 & 2,00 & 1 & 2,00 & 2 & 4,00 \\
\hline TOTAL. & 1,1 & 82,00 & 9 & 18,00 & 50 & 100,00 \\
\hline
\end{tabular}


OLIVEIRA, M.H.P. e Colaboradora - Avaliação Comparativa entre Duas Técnicas de Colheita de Urina para Cultura Bacteriológica em Mulheres. Rev. Bras. Enf.; DF, 35 : 39-47, 1982.

nica II e 8,8 minutos para a técnica I. Quanto ao valor unitário do material utilizado foi orçado para a técnica II em CrS 703,80 e para a técnica I em CrS 25,85

TABELA 2

PARECER DAS MULHERES QUANTO ÀS TÉCNICAS I E II

\begin{tabular}{|c|c|c|c|c|c|c|c|c|}
\hline TECNICAS & \multicolumn{2}{|c|}{ I } & \multicolumn{2}{|c|}{ II } & \multicolumn{2}{|c|}{ I E II } & \multicolumn{2}{|c|}{ TOTAL } \\
\hline PARECER & $F$ & $\%$ & $\mathrm{~F}$ & $\%$ & $\mathrm{~F}$ & $\%$ & $\mathrm{~F}$ & $\%$ \\
\hline Ficou mais à Vontade & 23 & 46,00 & & & & & 23 & 46,00 \\
\hline E mals Confortävel & 8 & 16,00 & & & & & 8 & 16,00 \\
\hline Indiferente & & & & & 7 & 14,00 & 7 & 14,00 \\
\hline Acha mais Limpa & & & 6 & 12,00 & & & 6 & 12,00 \\
\hline $\begin{array}{l}\text { Tanto faz, tive difi } \\
\text { culdade de urinar } \\
\text { nas duas }\end{array}$ & & & & & 1 & 2,00 & 1 & 2,00 \\
\hline $\begin{array}{l}\text { Porque è a enfermei- } \\
\text { ra que faz. }\end{array}$ & & & 2 & 4,00 & & & 2 & 4,00 \\
\hline $\begin{array}{l}\text { Tanto faz, eu quero } \\
\text { é descobrir o que } \\
\text { eu tenho. }\end{array}$ & & & & & 1 & 2,00 & 1 & 2,00 \\
\hline $\begin{array}{l}\text { Nāo Acredita no } \\
\text { Sabäo. }\end{array}$ & & & 2 & 4,00 & & & 2 & 4,00 \\
\hline TOTAL & 31 & 62,00 & 10 & 20,00 & 9 & 18,00 & 50 & 100,00 \\
\hline
\end{tabular}

TABELA 3

TEMPO GASTO PARA A EXECUÇÃO DAS TÉCNICAS I E II

\begin{tabular}{|c|c|c|c|c|}
\hline \multirow{2}{*}{ TEMPO TECNICAS } & \multicolumn{2}{|c|}{$I$} & \multicolumn{2}{c|}{ II } \\
\cline { 2 - 5 } EM MINUTO & $F$ & $\%$ & $F$ & $\%$ \\
\hline $51-10$ & 41 & 82,00 & - & - \\
\hline $101-15$ & 7 & 14,00 & 4 & 8,00 \\
\hline $151-20$ & 1 & 2,00 & 28 & 56,00 \\
\hline $201-25$ & - & - & 10 & 20,00 \\
\hline $251-30$ & 1 & 2,00 & 6 & 12,00 \\
\hline $301-35$ & - & - & 2 & 4,00 \\
\hline TOTAL & 50 & 100,00 & 50 & 100,00 \\
\hline
\end{tabular}


OLIVEIRA, M.H.P. e Colaboradora - Avaliação Comparativa entre Duas Técnicas de Colheita de Urina para Cultura Bacteriológica em Mulheres. Rev. Bras. Enf.; DF, $35: 39-47,1982$.

TABELA 4

MATERIAIS NECESSÁRIOS PARA A EXECUÇÃO DAS TÉNICAS I E II NO AMBULATÓRIO

\begin{tabular}{|c|c|c|c|}
\hline TECNICA I & & TECNICA II & \\
\hline $\begin{array}{l}\text { Pacote contendo o } \\
\text { Seguinte material } \\
\text { esterilizado: }\end{array}$ & & $\begin{array}{l}\text { Pacote contendo o } \\
\text { seguinte material } \\
\text { esterilizado: }\end{array}$ & \\
\hline 1. Tubo de ensaio & $\operatorname{cr} \$ 5,45$ & 1. Cuba rim & Cr\$ 220,00 \\
\hline 2. Rolha & $\operatorname{cr} \$ 0,20$ & 2. Cuba redonda & Cr\$ 90,00 \\
\hline \multirow[t]{5}{*}{ 3. Uma fralda } & $\operatorname{cr} \$ 20,00$ & 3. Pinça Pean & $\operatorname{cr} \$ 336,00$ \\
\hline & & 4. Tubo de ensaio & Cr\$ \\
\hline & & 5. Rolha & Cr\$ \\
\hline & & 6. 6 Gazes & Cr\$ \\
\hline & & 7. 10 bolas de algodão & Cr\$ 0,50 \\
\hline Sub. Total & $\operatorname{cr} \$ 25,65$ & Sub. Total & $\operatorname{cr} \$ 645,85$ \\
\hline \multirow[t]{3}{*}{ Satão Neutro } & $\operatorname{cr} \$ 0,20$ & I par de luvas & Cr\$ 45,00 \\
\hline & & $40 \mathrm{ml}$ de sterylderm & $\operatorname{cr} \$ 2,45$ \\
\hline & & $40 \mathrm{mlde}$ söro fisiolögro & $\operatorname{crs} \quad 1,50$ \\
\hline TOTAL & $\operatorname{cr} \$ 25,35$ & TOTAL & $\operatorname{Cr} \$ 703,80$ \\
\hline
\end{tabular}

GRÁFICO I - Resultados microbiológicos das uroculturas agrupadas segundo os conceitos: negativo, duvidoso e positivo.

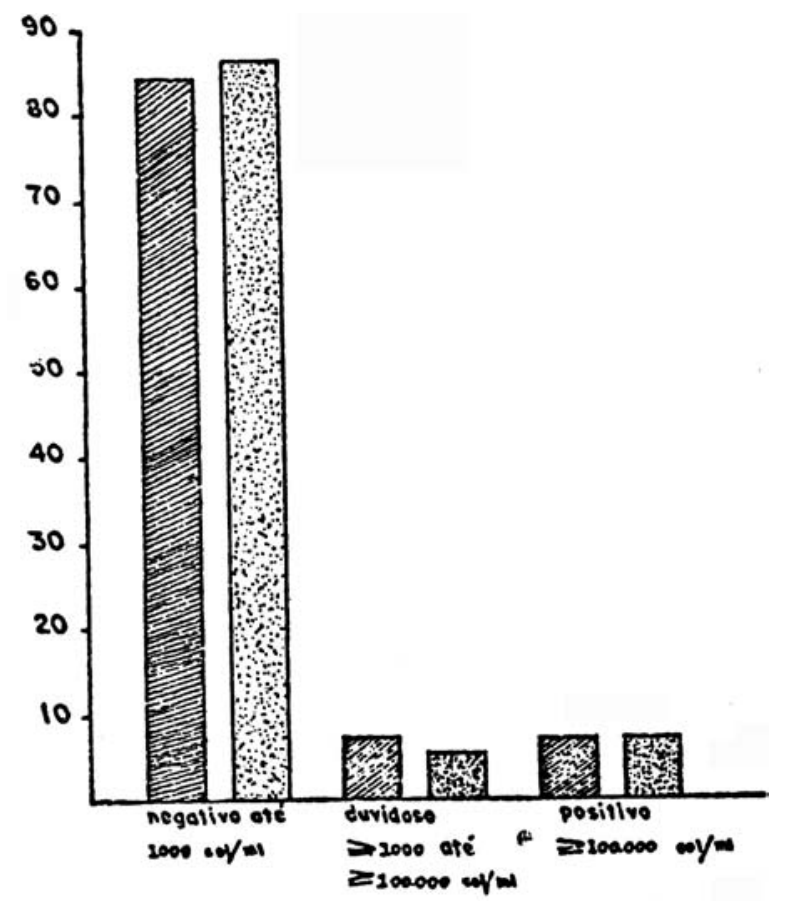


OLIVEIRA, M.H.P. e Colaboradora - Avaliação Comparativa entre Duas Técnicas de Colheita de Urina para Cultura Bacteriológica em Mulheres. Rev. Bras. Enf.; DF, $35: 39-47,1982$.

\section{B I B L I O G R A F I A}

1. ALMEIDA, S. S. - Tratamento das infecçōes urinárias. Rev. Clin. Med. $1(4): 33-48,1987$.

2. ANGERAMI, E. L. S.; BOEMER, M. R. - Análise bacteriológica de amostras de urina coletadas com técnica distintas. Rev. Enf. Novas Dimensỏes. 2(1) :28-33, 1978.

3. BRUNE, L. S.; SUDDARTH, D. S. Enfermagem Médico-Cirúrgica. $\mathbf{3}^{\mathrm{a}}$ ed. (Rio de Janeiro), Interamericana (1978), págs. 682-685.

4. COIMBRA, M. S. R. - Infecçōes das vias urinárias. Atualidades Médicas. $11(12): 20-26,1976$.

5. DAGUET, G. L. - Técnicas em bacteriologia. I Seróbios - Barcelona. Editorial Jins. 1977, págs. 82-86.

6. DU GAS, B. W. - Enfermagem prática. 3. ${ }^{a}$ ed. Rio de Janeiro. Interamericana, págs. 420-435, 1978.

7. KOURANY, M. - Obtención y manejo de muestras para exámenes microbiológicos de las enfermedades transmissibles. Publicacions cientifica. 326, 38-39, 1976.

8. KUNIN, C. M. - Infecciones urinárias - Diagnóstico, profilaxis y tratamiento. Barcelona, Toray, 1973.
9. LESSA, I. - Infecçōes urinálías em Escolares de Salvador. Rev. Med. Bahia. 23(3) :177-187, 1977.

10. MASSON, M. A. - Enfermagem Médico-Cirúrgica. 3. ${ }^{\mathrm{a}}$ ed. Rio de Janeiro, Interamericana, 1976, págs. 314-336.

11. OLIVEIRA, PESSINI, M. H. - Estudo comparativo entre duas técnicas de colheita de urina para cultura bacteriológica em mulheres. Dissertação de Mestrado apresentado ao Departamento de Enfermagem Geral e Especializada. Escola de Enfermagem de Ribeirão Preto da Universidade de São Paulo. Ribeirão Preto, 1979.

12. RUBERT, A. - Urine 1. Nurs. Tim 15, 25-28, 1977.

13. ROCHA, H. - Uso e abuso do cateterismo Rev. Clin. Med. 1(12) :44-52, 1968.

14. SOUTO, C. A. V.; LISBOA, J. F. E. Atualização sobre infecção urinária J. Bras. Urol. (Rio Grande do Sul) 3 255-263, 1977. 